\title{
EXPLORATION AND ANALYSIS OF THE DEVELOPMENT PATH OF NICHE SPORTS INDUSTRY FROM THE PERSPECTIVE OF MARKETING AND PROMOTION
}

\author{
${ }^{1}$ Xuanyu Meng, ${ }^{2}$ Kejia Zhang \\ ${ }^{1,2}$ School of International Business, Shandong Technology and Business University, Yantai, China \\ DOI: 10.46609/IJSSER.2020.v05i08.003 URL: https://doi.org/10.46609/IJSSER.2020.v05i08.003
}

\begin{abstract}
Since the economic crisis in 2008, the global economy has been on the rise in most countries, with disposable income and consumption levels much higher than those of a decade ago, and a preference for physical exercise in free time. So the potential customer group in niche sports is also kept expanding. How to promote niche sports and develop niche sports market with great potential becomes an urgent problem. A niche sport may be popular around the world because of a movie or a competition, but there is a need to increase mass participation if we want to maintain long-term stable development. This article will discuss the development of niche sports industry from the perspective of marketing and promotion and study its path selection for the future.
\end{abstract}

Keywords: Development path of the industry, Niche sports promotion, 4 p marketing theory

\section{Introduction}

"Long tail theory" refers to the convergence of many niche markets can also produce the market flow which can match the mainstream market. From the "long tail theory", currently, the mass sports occupies the leading end of the demand curve, with high attention, large market space, and recognized by the public. But the niche sport is at the end of demand curve, with less attention and less public participation. This has a great relationship with the high threshold of niche sports consumption and narrow popularization. In the 21 st century of rapid economic development, people's consumption level has been raised, the consumption demand is more diversified, and the consumption concept has been changed with it. The rising incomes of residents have prompted a rapid rise in the middle class. The demand for fashion consumption, leisure consumption and enjoyment consumption is increasing around the world. And niche sports such as rock climbing, skiing, racing, equestrian, ice hockey and so on are slowly come into our lives 
because of "fashion" and "unique", understood by more people through new media and other ways, and attracting people of different ages to participate in it. From the previous no demand to today's hot, the development of niche sports cannot be separated from the high-quality economic development, the expansion of Internet marketing channels and the support of relevant policies.

\section{GDP added value of sports industry in various countries}

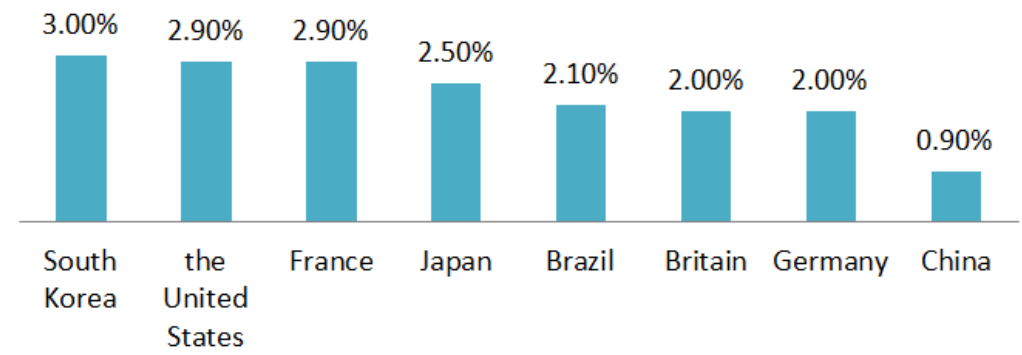

Geographical location, climate environment and other natural conditions are important factors affecting the development of niche sports industry. Ice hockey originated in Canada, but Finland, with a population of only 5 million, is one of the most developed countries in the world. This is affected by economic, cultural and other factors, but also by some natural reasons, including cold and humid climate, flat terrain and so on. In Finland, children often play ice hockey on a field near their yard, and while playing, they also lay the groundwork for better practice of ice hockey in the future. The support of national policy and the Finnish love of ice hockey have all contributed to the development of ice hockey in Finland.

In addition, with the continuous progress of technology, modern art plays an important role in the development of niche sports. The Indian film "Wrestling! Dad" on 2017 is adapted based on a real story of the former wrestling champion Singh training two daughters to become women wrestling champion. The final harvest was 54 billion rupees from India and \$12.39 million from North America. During the release of the film, the audience has a great interest in wrestling, and many people take the initiative to understand the relevant information about wrestling competition, which helped to expand the influence of wrestling.

With the enrichment of the connotation of niche sports, the improvement of rules and the expansion of related markets, the influence of niche sports in the word cannot be underestimated. For the benign development of niche sports industry, relevant enterprises should make good use of the existing favorable conditions, use the Internet to expand the communication power and influence, guide consumers to experience and participate actively, and cultivate their 


\section{International Journal of Social Science and Economic Research}

ISSN: $2455-8834$

Volume:05, Issue:08 "August 2020"

consumption consciousness in related industries. In the context of the United Nations and the World Health Organization to encourage people to participate in sports, the merchant should develop and expand the related industrial chains to make the niche sports more suitable for the consumption needs of the world's residents. While promoting economic development, let sports spirit more deeply rooted in people's hearts.

\section{A PEST Analysis on the Development of niche Sports Industry}

To promote the development of niche sports industry, we need to analyze the big picture faced by enterprises in order to get the target. Generally speaking, the development of niche sports industry is in a suitable environment with less external restrictions. The official policy support, the economic improving development and the level of science and technology, and people's attention to sports have made a positive impact on the development of niche sports. Infra, I will use the PEST analysis method from four parts to analyze the present development situation of niche sports, the political environment, the economic environment, the social environment, and the technical environment.

\subsection{Political environment}

In recent years, niche sports events have been gradually recognized by the official, and appear in the public view. On 11 December 2014, the United Nations declared the 21 June of each year as the International Day of Yoga. In 2016, the International Olympic Committee voted to announce that five major events, including skateboarding, surfing, rock climbing, karate and baseball and softball, were officially entered into the 2020 Tokyo Olympic Games in Japan. These previously niche movements are gaining more international influence. Governments also actively promote policies to support the development of niche sports, and the living environment of niche sports is gradually improving.

\subsection{Economic Environment}

At the beginning of this century, the global economy entered a period of rapid development, with the growth of GDP (Gross Domestic Product) more than 6.0\% in many countries. The PCDI (Per Capita Disposable Income) of each country has also increased, and people have additional funds to participate in niche sports such as skateboarding and skiing. From the macroeconomic data, the number of middle class in some developed countries accounts for more than half of the number of people, so the people are more inclined to improve the quality of life, having a higher enthusiasm to participate in niche sports, and the per capita consumption on sports shows a rapid growth trend. 


\subsection{Social Environment}

The successful development of niche sports cannot be separated from the social participation, which is closely related to the local residents' law of lives, living habits and other social factors. If a niche sport is very popular in a region, it proves that it is consistent with the local social environment. According to statistics, there are 11 million to 15 million ski lovers in Japan, accounting for $10 \%$ of the total population, an average of 3-4 times a year ski per person. Because of division of labor in society and other reasons, Japanese women and the elderly have a lot of leisure time, which can fully meet the requirements of participating in skiing. So among Japanese skiers, women and the elderly take a relatively very high percentage and keep increasing.

\section{Growth prospects of sports market}

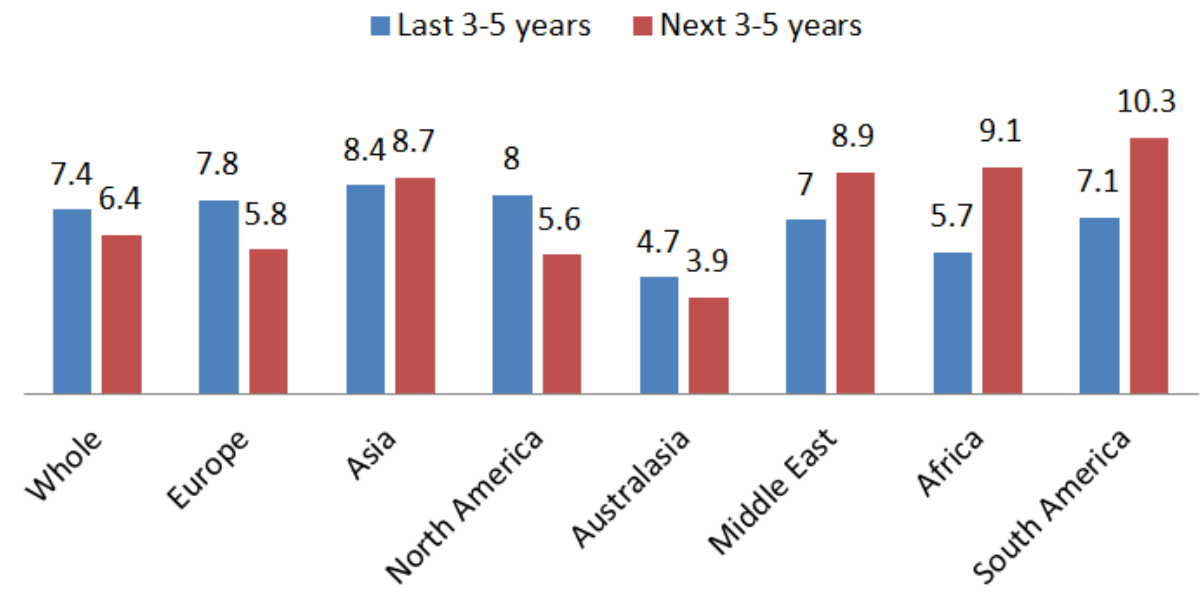

\subsection{Technical environment}

In order to stimulate the consumption enthusiasm of consumer, and raise the popularity, realize the profit maximization at the same time, many international enterprises and clubs about diving, skiing, rock climbing and cycling and other niche sports have taken measures to improve the safety and experience of the project. For example, PADI (Professional Association of Diving Instructors) is one of the world's largest diving training organizations, with more than 6600 submersible stores and 130,000 coaches in 183 countries around the world, combining outdoor sports and daily life closely through cross-border cooperation, helping consumers to remove tension during the experience as far as possible, and establishing specialized testing institutions to regularly and comprehensively screen safety devices. 


\section{International Journal of Social Science and Economic Research}

ISSN: $2455-8834$

Volume:05, Issue:08 "August 2020"

\section{Integrated Programme of Marketing of the Niche Sports}

Expand the comprehensive influence of niche sports. Spread its attitude to the sports and life concept, healthy, full of confidence, dare to challenge, and overcome difficulties. Attract the public to have more understanding of it. Gather niche sports enthusiasts. Provide a mass base for the development of niche sports and promote the development of its product industry chain. We can take OTO (Online to Offline) and flexible use of new media technology program to get this above.

\subsection{Marketing Law of 4P}

Production: If niche sports want to attract more participants, the product must be unique enough first. In the process of product development, explore the unique characteristics and take this as a selling point, pay attention to the profession and function of products, such as sports clothing, professional equipment, sports equipment, training courses and so on. At present, products of niche sports exist polarization situation. On the one hand, the high-end and advanced product projects for professionals and high-income people have been relatively perfect. On the other hand, the primary product projects for beginners, middle and low income groups are still relatively short. Grasping the characteristics of product, developing more pro-people niche sports products, and filling the gap in the market is an effective way to attract audiences quickly.

Price: The cost of participating in most niche sports is too high. Custom-made courses and professional equipment all need a lot of money. At the same time, some businesses pursue to upgrade the brand grade blindly, setting high price, to withdraw some new people who have wanted to get started. Now the niche sports industry needs to reduce the unreasonable pricing situation first, standardize the market order, at the same time reduce the $R$ \& $D$ (Research and Development) costs from the professional point of view, expand the affordable market, set the appropriate price for different groups of people, and achieve the large area coverage of the potential audience.

Channels: With the increasing of the customers of niche sports, enterprises cannot face consumers directly and need dealers as the medium between them. At that time, they need a channel to connect. For example, a sports club that integrates teaching, practice and sales can be opened. Consumers can do sports activities in the club and choose the products they need. The centralized management of the club is also conducive to the enterprise to recover information, formulate a targeted development plan, and make transmission channels of information.

Publicity: With the popularity of the Internet and the rise of social platforms such as Facebook, people around the world are connected through the network, which is also an excellent platform for niche sports publicity in the future. There should also be a focus in the publicity process, for 


\section{International Journal of Social Science and Economic Research}

ISSN: $2455-8834$

Volume:05, Issue:08 "August 2020"

example, businesses can provide free photography and video services, and uploaded retouching and artistic videos to the network to promote and attract more customers. Also business can use the network platform to launch offline competitions, and record by living, stimulating people's interest in niche sports from the highly technical competition.

\subsection{Using Emerging Internet Technologies}

Network promotion: With the arrival of the network age, taking the good use of network promotion to drive marketing is essential. With the help of short video platform, social media and so on to promote and cooperation with the bloggers or platforms having flow, business can push basic knowledge explanation of the project, difficult technology analysis, interesting story during the development and other related content, arousing the interest of users in niche sports all-round, so as to drive the efficient output of the end products of the industrial chain.

Development of a Network Platform: The advances in network technology provide convenience for the production of web pages or applications. Creating platforms or APP to share different types of knowledge for niche sports, with sub distinguished by motion type, facing the world attracting niche sports enthusiasts and potential customers and making them to apply for a platform account online where can record and share their sports story, on one hand, brings the new one who has interest to deep learn this sport, on the other hand, can recommend the suitable venue for the people interested in or organize a game or show. Through online and offline, expend the impact, and call for more participation. The official account can also regularly publishes large-scale activities on the platform, and awards customized commemorative badges, medals, prizes and so on to active users according to their participation.

Integrate with the Entertainment Industry: With the continuous development of VR and game production technology, people can easily enjoy simulation sports at home when it is not convenient to go out. The combination of e-sports and sports has become the general trend of the sports industry today. For example, the MotoGP (World Motorcycle Grand Prix) in 2020 cannot be held as scheduled. The organizers through the official video games convened star drivers and world champions to compete online. It not only retains the sports audiences who have no game to watch, but also opens a new door for the development of the industry. When attracting the game lover to understand the motorcycle race, the game management can also bring the very considerable income, truly achieving a win-win cooperation.

\subsection{Global Marketing Strategy}

Use the trend of globalization to seek deep expansion and pay full attention to sinking markets. Not only in the country of origin of the sport, but also in order to push the brand of niche sports to the world, different marketing strategy in different countries should be made. Products with 


\section{International Journal of Social Science and Economic Research}

ISSN: $2455-8834$

Volume:05, Issue:08 "August 2020"

regional characteristics should be reached further when producing the standardized productions. The customization of ads and the choice of distribution channel should be based on regional consumption level and local consumer behavior patterns. For example, Adidas, a well-known sports brand, launched a Chinese style Spring Festival creative advertising on baseball series. The stars are dressed in sportswear that combines the Chinese spirit beast, the Chinese flower, the Chinese 12- chapter pattern and the Chinese traditional totem element.As soon as the advertisement went online, it immediately triggered a heated discussion among online friends and attracted many people to buy it.

\subsection{Consumer-oriented Marketing Strategy}

With the increasing individuation of consumption demand, enterprises should investigate the participation of the masses in various types of niche movements in recent years, analyze the main customer of their products in detail, carry out targeted design planning and carry out customized marketing according to the specific requirements of each customer, and then reform, innovate and improve the products of the niche movements they operate, and provide better services for users. The formulation of price strategy in marketing should fully consider the consumer's view of consumption and the price range that consumers can bear. Analyze and survey the monthly income of consumers and make a summary. Set the most reasonable price for the type of exercise. Use the combination of traditional marketing and network marketing to achieve mutual benefit. Enterprises should fully analyze and master the purchasing concept of consumers and realize the full communication between the two sides.

\section{Summary}

In a word, the external development environment of niche sports industry is good at present, and the internal industry needs to further optimize and improve the products, organization mode, propaganda mode and so on. Maintain the existing advantages of high-end product lines, at the same time expand the affordable market. Targeted to different groups of people to develop products. Integrate the existing organizational model, and make the information channels ordered and systematic. Make full use of Internet technology, increase publicity efforts, and add new propaganda platform. It is an important breakthrough for the development of niche sports industry to cover most or even all of the potential audience.

\section{References}

[1]. Gashaw Abeza,Norm O'Reilly,Mark Dottori,Benoit Séguin,Ornella Nzindukiyimana. Mixed methods research in sport marketing[J]. International Journal of Multiple Research Approaches,2015,9(1). 
[2]. Edson Coutinho da Silva,Alexandre Luzzi Las Casas. Sports Marketing Plan: An Alternative Framework for Sports Club[J]. International Journal of Marketing Studies,2017,9(4).

[3]. Rajan Varadarajan. Strategic marketing, marketing strategy and market strategy[J]. AMS Review,2015,5(3-4).

[4]. Vanessa Ratten,Hamish Ratten. International sport marketing: practical and future research implications[J]. Journal of Business \&amp; Industrial Marketing,2011,26(8).

[5]. Bo Rundh. Rethinking the international marketing strategy: new dimensions in a competitive market[J]. Marketing Intelligence \&amp; Planning,2003,21(4). 